\title{
APPLICATION OF MULTIVARIATE ANALYSIS TO DIFFERENTIATE HARARGHE HIGHLAND GOAT POPULATIONS REARED IN THE WEST HARARGHE ZONE, ETHIOPIA
}

\author{
Alefe Takele $^{1,2 *}$, Aberra Melesse ${ }^{2}$, and Mestawet Taye ${ }^{3}$ \\ ${ }^{1}$ Oda Bultum University, College of Agriculture, Department of Animal Sciences, P.O. Box 226, Chiro, \\ Ethiopia \\ https://orcid.org/0000-0002-4510-4837 \\ ${ }^{2}$ Hawassa University, College of Agriculture, School of Animal and Range Sciences, P.O. Box 05, \\ Hawassa, Ethiopia \\ http://orcid.org/0000-0003-4653-0587 \\ ${ }^{3}$ Hawassa University, College of Agriculture, School of Animal and Range Sciences, P.O. Box 05, \\ Hawassa, Ethiopia \\ http://orcid.org/0000-0002-3461-5738 \\ *Correspondence e-mail: alefe.takele@obu.edu.et
}

\section{ABSTRACT}

Multivariate analysis of morphological variables has been successfully used to estimate genetic variation within and between local breeds. The objective of this study was to differentiate Hararghe highland goat populations based on their morphometric traits by applying multivariate analysis. Sixteen morphometric traits were collected from 450 goats reared in the three agroecological zones (highland, midland and lowland) of West Hararghe. Multivariate canonical discriminant analysis in combination with cluster and discriminant analysis was applied to identify the combination of variables that differentiate goats of the three agroecological zones. The results indicated that all the morphometric traits were significantly affected by age. The cluster analysis indicated that two main groups of midland goats were included in one group, while group two included highland and lowland goats under one sub-cluster. The canonical discriminant analysis identified two canonical variables (CAN) of which CAN1 and CAN2 accounted for 68.2 and $31.8 \%$ of the total variation, respectively. The quadratic discriminant analysis correctly assigned the respective $71.3,77.3$, and $81.3 \%$ of lowland, midland, and highland goat populations into their source populations, with an overall accuracy rate of $76.7 \%$. The Mahalanobis distance verified that lowland and highland goats are the closest, while midland and highland goats were the furthest. However, the canonical discriminant analysis indicated a visible overlapping between goat populations of the three agroecological zones, indicating the existence of homogeneity among them. In conclusion, multivariate analysis identified 11 morphometric traits as the most imperative traits to differentiate Hararghe highland goat populations effectively. Genetic potentials of Hararghe highland goat populations can be improved through community-based breeding programs for their sustainable utilization and conservation.

Key words: Agroecology, discriminant analysis, cluster analysis, morphometric traits. 


\section{INTRODUCTION}

Ethiopia is home to the second largest goat populations after cattle, reaching 50.5 million heads (CSA, 2020). The country is situated on the route of human migration from Eurasia to the African continent, and therefore there is a great livestock diversity in the region (Mekuriaw, 2016). The country has diverse agroclimatic conditions and due to adaptation potential, several livestock breeds have been reported (IBC, 2004). In fact, goats significantly contribute to the livelihood of the resource-challenged society of the tropics, such as Ethiopia (Haile et al., 2019).

About $99.88 \%$ of Ethiopia's goat population is indigenous (CSA, 2020), being phenotypically classified into 13 major distinct types (Gizaw, 2009). However, a recent genetic characterization revealed the presence of only seven distinctively different breeds in the country (Mekuriaw, 2016). To date there is limited information on the real genetic potentials of indigenous goat populations distributed in various regions of the country. However, information on their morphological characteristics is essential for sustainable improvement, utilization, and conservation of the breeds (Melesse et al., 2013). In addition, morphological variables are important in breed identification and classification. Multivariate analysis of variance is used to determine the traits required for distinguishing between and within animal populations, and for assessing the aggregate morphometrical traits needed for grouping (FAO, 2012).

A study conducted by Tsegaye et al. (2013) described the production systems and some phenotypic characteristics of Hararghe highland (HH) goat populations (Tsegaye et al., 2013). The authors indicated that, to the best of their knowledge, no previous works had reported on the characterization of local $\mathrm{HH}$ goat populations by applying multivariate analysis. Multivariate analysis of morphological variables has been successfully used to estimate genetic variation within and between local breeds (Yakubu et al., 2011). Morphological distances between and within $\mathrm{HH}$ goat populations across agroecological zones (highland, midland and lowland), which could serve as a basis for their genetic improvement, have not been established. Therefore, to establish the extent of genetic variation and/or adaptive phenotypic plasticity of $\mathrm{HH}$ goats, the present study examined the morphometric trait relationships between and within $\mathrm{HH}$ goat populations of three agroecological zones using multivariate analysis. This is a crucial step towards their proper management, conservation, and improvement of breeding programs and selection schemes. Therefore, the objective of study was to differentiate $\mathrm{HH}$ goat populations based on their morphometric traits by applying multivariate analysis.

\section{MATERIALS AND METHODS}

\section{Study area}

The study was conducted in the West Hararghe zone of the Oromia National Regional state of Ethiopia. It is situated between $7^{0} 41^{\prime} 9^{\prime \prime}$ and $9^{\circ} 14^{\prime} 27^{\prime \prime} \mathrm{N}$ latitude and $40^{\circ} 9^{\prime} 41^{\prime \prime}$ and $41^{\circ} 41^{\prime} 4^{\prime \prime}$ E longitudes. Its altitude ranges from 598 to 3079 m.a.s.l. The West Hararghe zone was selected purposively for this study to address $\mathrm{HH}$ goat breeds in different agroecological zones and farming systems. In the study area, about $85 \%$ of the population practice subsistence agriculture and livestock production. This area is characterized by three agroecological zones: highland, midland and lowland (ZARDO, 2017). The total livestock population in the zone is estimated to be about 2.38 million heads, of which $39.09 \%$ are goats (CSA, 2020).

\section{Site selection and sampling strategy}

A multistage sampling technique was applied to select representative samples from each stratum. In the first stage, 3 districts representing the three agroecological zones (low-, mid- and highland) were selected from the West Hararghe zone by considering their potentials for goat production. In the second stage, two kebeles (the smallest administrative unit within the district) from each district were selected based on the distribution of goat population size as compared with goat population from other kebeles. In the third stage, the households who own goats (at least three matured goats) and had enough experience in rearing goats were identified within kebeles. Accordingly, a total number of 450 (327 females and 123 males) were sampled as follows: 150 goats (115 females and 35 males) from lowlands; 150 goats (103 females and 47 males) from highlands; and 150 goats (109 female and 41 males) from midlands. The owner's recall method along with dentition classes (pairs of permanent incisors, PPI) was used to estimate the age of goats. Thus, goats with OPPI (milk teeth), 1PPI, 2PPI, 3PPI and 4PPI were classified into post-weaning, yearling, 2-year-old, 3-year-old, and 4-year-old, respectively (Ebert and Solaiman, 2010). Each animal was further identified by sex, age and sampling site (agroecological zone). The study was conducted from September 2019 to December 2019. 


\section{Data collection procedures}

Data were scored on 16 morphometric traits following the descriptor list of FAO (2012) for phenotypic characterizations of goats. Accordingly, the following traits were measured: body weight (BW), heart girth (HG), height at withers (HW), body length (BL), rump height $(\mathrm{RH})$, paunch girth (PG), chest depth (CD), chest width $(\mathrm{CW})$, sternum height $(\mathrm{SH})$, rump width (RW), rump length (RL), head width (HDW), head length (HDL), neck length (NL), tail length (TL), and ear length (EL). All measurements were made using a plastic measuring tape, while the BW was taken using a suspended weighing scale with $50 \mathrm{~kg}$ capacity by placing each animal in a self-devised holding harness. Goats were sampled early in the morning prior to grazing to avoid the effect of feeding and watering on the animal's size and conformation. Measurements were made by the same person to avoid human error in each study site and were also restricted to healthy, non-pregnant and non-castrate goats.

\section{Statistical analysis}

Data on morphometric traits were subjected to GLM procedures of Statistical Analysis System (SAS, 2012 ver. 9.4) by fitting sex, age and agroecological zone as fixed effects. When F-test declared significant, multiple least-square means were then compared with the Tukey-Kramer test. The following model was used for analysis of morphometric traits.

$Y_{i j k}=m+A_{i}+S_{j}+B_{k}+e_{i j k}$

Where:

$\mathrm{Y}_{\mathrm{ijk}}=$ response variables observed at the $\mathrm{i}^{\text {thage }}$ group, $j^{\text {th }}$ sex and $\mathrm{k}^{\text {th }}$ agroecological zone

$\mathrm{m}=$ overall mean,

$A_{i}=$ the effect of $i^{\text {th }}$ age group ( $i=0,1,2,3$ and 4) PPI

$S=$ the effect of $j^{\text {th }}$ sex $(j=$ female and male)

$\mathrm{B}_{\mathrm{k}}=$ the effect of $\mathrm{k}^{\text {th }}$ agroecological zone $(\mathrm{k}=$ lowland, midland and highland)

$\mathrm{e}_{\mathrm{ij \textrm {k }}}=$ random residual error

The best-fitted regression models were selected based on the highest coefficient of determination $\mathrm{R}^{2}$ value and the smallest Mallows' C parameter value to predict live body weight of the goats from the other morphometric traits. Body weight was then predicted by including those traits that showed high correlation with body weight using stepwise multiple linear regression procedure with the following model:

$\mathrm{Y}_{j}=\beta_{0}+\beta_{1} \mathrm{X}_{1}+\beta_{2} \mathrm{X}_{2}+\ldots \ldots \ldots \beta_{\mathrm{n}} \mathrm{X}_{\mathrm{n}}+\mathrm{e}_{j}$

Where:

$\mathrm{Y}_{j}=$ the response variable $(\mathrm{BW})$; $\beta_{0}=$ the intercept;

$\mathrm{X}_{1}, \mathrm{X}_{2}, \ldots . . \mathrm{X}_{\mathrm{n}}=$ the explanatory variables (HG, BL, (.... $\left.X_{\mathrm{n}}\right)$;

$\beta_{1}, \beta_{2}, \ldots \ldots . \beta_{n}=$ regression coefficients of the explanatory variables $\mathrm{X}_{1}, \mathrm{X}_{2}, \ldots \mathrm{X}_{\mathrm{n}}$;

$\mathrm{e}_{j}=$ random residual error

Multivariate analysis, such as stepwise multiple linear regression, cluster, stepwise discriminant, canonical discriminant, and quadratic discriminant analysis, was applied on morphometric traits to describe and differentiate the studied goat populations (FAO, 2012). The procedure of cluster analysis was performed and a dendrogram was constructed based on Euclidean distance to differentiate goat populations of the three agroecological zones using the average linkage method to group the flocks into their morphological similarity. Moreover, the stepwise discriminant analysis was applied using the STEPDISC procedure to determine which morphometrical traits have more discriminating power. The relative importance of the morphometric variables in discriminating highland, midland and lowland goat populations was assessed using level of significance, F-statistic and partial $\mathrm{R}^{2}$. Collinearity among the variables used in the discriminant model was evaluated using tolerance statistics. The canonical discriminant analysis was then performed using the CANDISC procedure to compute the Mahalanobis distances between class means, uni- and multivariate statistics, canonical variables and eigenvalues. The TEMPLATE and SGRENDER procedures were also applied to create a plot of the first two canonical variables in a scatter graph for visual interpretation. Finally, quadratic discriminant analysis of the DISCRIM procedure was conducted to determine the percentage classification of goats into their source populations using quadratic discriminant function. The classification accuracy of the discriminant analysis was further cross-validated by invoking the CROSSVALIDATE option. All multivariate analyses were performed using the statistical software analysis system (SAS, 2012, ver. 9.4).

\section{RESULTS AND DISCUSSION}

\section{Morphometric traits}

Knowledge of these morphometric traits is important to implement genetic improvement (selection), appreciate variations among goat populations to facilitate their sustainable use, and estimate body weight from simple and more easily measurable variables as well as market value in terms of animal cost (Gatew, 2014). The least-squares means of body weight and other 
morphometric traits of HH goat types by sex, age, and agroecological zone are presented in Table 1. The results of the study indicated that sex revealed a significant effect $(p<0.05)$ on HG, PG, CD, RW, RL, HDW and NL. The influence of sex on the morphometric traits in the present study are likely related to sexual dimorphism, which lead to differential growth rates (Carneiro et al. 2010). Age had significant effects ( $p<$ 0.05 ) on all morphometric traits; as goat's age increased, morphometric traits also increased. The current results agree with those of Yemane et al. (2020) and Ahmed et al. (2016) for indigenous goats of Ethiopia, who reported that all body measurements increased as age group increased. Similarly, Kurnianto et al. (2013) reported that most of the body dimensions of mature goats were higher than those of young goats, paralleling with growth and development of morphometric traits of local goats in central Java, Indonesia. A linear increment of morphometric variables with age indicates a normal body development of goats, which shows suitability of the production environment for goat rearing. The results of the study further indicated that all the morphometric traits (except for BW, RW and RL) were affected $(p<0.05)$ by agroecological zone. Accordingly, lowland and highland goats had higher $(p<0.05) \mathrm{HG}, \mathrm{RH}, \mathrm{CW}, \mathrm{SH}$, and HDW values than midland goats. The HG, $\mathrm{CD}$ and NL values of highland goats were higher $(p<0.05)$ than lowland and midland goats. The highest BL and HDL values were observed in lowlands followed by highlands and midlands, being significantly different $(p<0.05)$ from each other. The highest PG values were recorded in lowland goats and differed $(p<0.05)$ from those of the other two agroecological zones. The shortest EL was observed in the highland goats and differed from the values observed in the two agroecological zones $(p<0.05)$. The difference in morphometric traits between zones might result from different management practices by goat producers and availability of feed resources (Melesse et al., 2013). Moreover, the production environment in different agroecological zones could have influenced the adaptative potentials of goats and their performance (Melesse et al., 2021).

\section{Multivariate analysis}

\section{Predicting live body weight}

Best-fitted regression models to predict live body weight from other morphometric traits of male and female $\mathrm{HH}$ goats are presented in Table 2. In order to predict live body weight from other morphometric traits, stepwise multiple linear regression analysis was carried out for female and male goats separately based on explanatory variables, which had a positive correlation with body weight. The small sample size of male goats in this study might have decreased the accuracy of the result if separate age groups were used. Thus, instead of using a separate equation for different age groups, it seems logical to pool age groups for the prediction of BW, which could be based on the regression equation $\mathrm{BW}=-36.45+$ $0.91 \mathrm{HG}$; and $\mathrm{BW}=-34.37+0.92 \mathrm{HG}$ for female and male goats, respectively (Fig. 1 and 2).

Prediction of live body weight can be useful for local farmers to make selection and cull decisions as it can be relatively low cost, highly accurate and consistent (Musa et al. 2012). There is often a great need for livestock herdsmen to know how much their animals weigh for both breeding and marketing purposes. In this study, stepwise multiple linear regression analysis revealed that heart girth was more consistent in predicting live body weight than other morphometric traits in both sexes. The better association of body weight with heart girth was possibly due to the relatively larger contribution of heart girth to body weight, which consists of bones, muscles, and viscera (Melesse et al., 2013; Ahmed et al., 2016).

\section{Cluster analysis}

As indicated in Fig. 3, the cluster analysis generated a phylogenetic tree that clustered the $\mathrm{HH}$ goat populations reared in the West Hararghe zone into two main groups based on morphometric traits. The first cluster included goat populations from midlands, while the second cluster includes goats from both highlands and lowlands as subcluster. This observation indicates that highland and lowland goats are much closer to each other than those of the midland goats and confirms the results of the cross-classification of population distribution with discriminant analysis.

\section{Stepwise discriminant analysis}

A summary of stepwise discriminant analysis for selection of traits is presented in Table 3. Sixteen morphometric traits for both sexes were subjected to the STEPDISC procedure and 11 of them were identified as suitable discriminating traits in stepwise selection. The relative importance of the identified morphometric traits in discriminating power of the three goat populations was assessed at $15 \%$ level of significance. Wilk's lambda test confirmed that all the selected variables had a highly significant $(p<0.0001)$ contribution to discriminate the total population into separate groups.

Wilk's Lambda dropped to 0.403 with a significant difference between goat populations of the three agroecological zones $(F=3.67 ; p<0.05)$, 


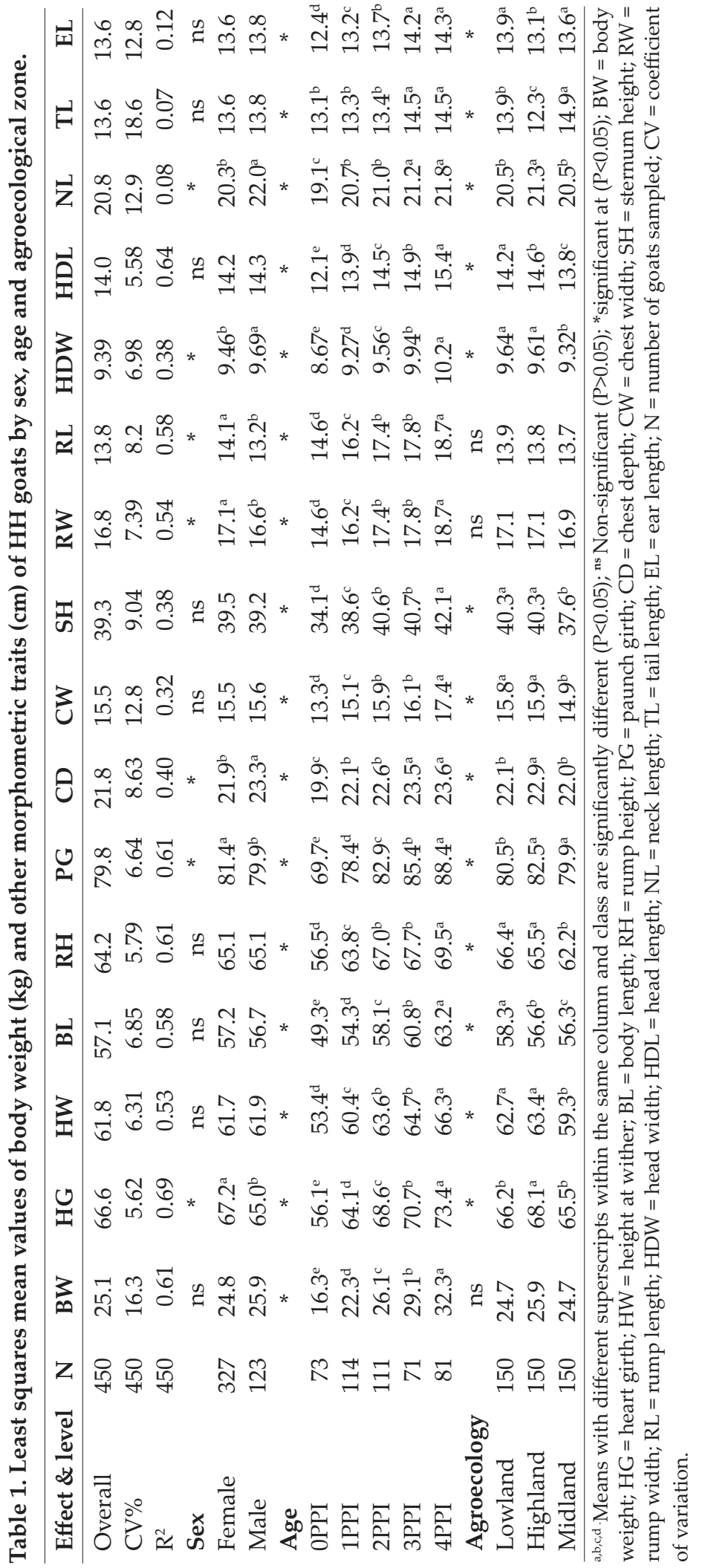


Table 2. Best-fitted regression models to predict live body weight from other morphometric traits of male and female Hararghe highland goats.

\begin{tabular}{lcccccrcr}
\hline & \multicolumn{9}{c}{ Parameter estimate } & & \\
\cline { 3 - 5 } Model & $\mathbf{I}\left(\boldsymbol{\beta}_{\mathbf{0}}\right)$ & $\boldsymbol{\beta}_{1}$ & $\boldsymbol{\beta}_{2}$ & $\boldsymbol{\beta}_{3}$ & $\mathbf{R}^{2}$ & $\mathbf{C}(\mathbf{P})$ & P-value \\
\hline Female & & & & & 0.88 & 306.64 & $<.0001$ \\
$\quad$ HG & -36.45 & 0.91 & & & 0.93 & 16.13 & $<.0001$ \\
HG+BL & -39.92 & 0.64 & 0.37 & & & & \\
Male & & & & & 0.83 & 115.93 & $<.0001$ \\
HG & -34.37 & 0.92 & & & 0.86 & 72.12 & $<.0001$ \\
HG+BL & -37.83 & 0.58 & 0.45 & & 0.89 & 35.08 & $<.0001$ \\
HG+BL+CD & -43.99 & 0.33 & 0.44 & 0.96 & 0.89 \\
\hline
\end{tabular}

$\mathrm{I}\left(\beta_{0}\right)=$ Intercept; $\beta_{1}-\beta_{3}=$ Regression coefficients; $\mathrm{R}^{2}=$ model R-square; $\mathrm{C}(\mathrm{P})=$ the Mallows $\mathrm{C}$ parameters; $\mathrm{HG}=$ heart girth; $\mathrm{BL}=$ body length; $\mathrm{CD}=$ chest depth.

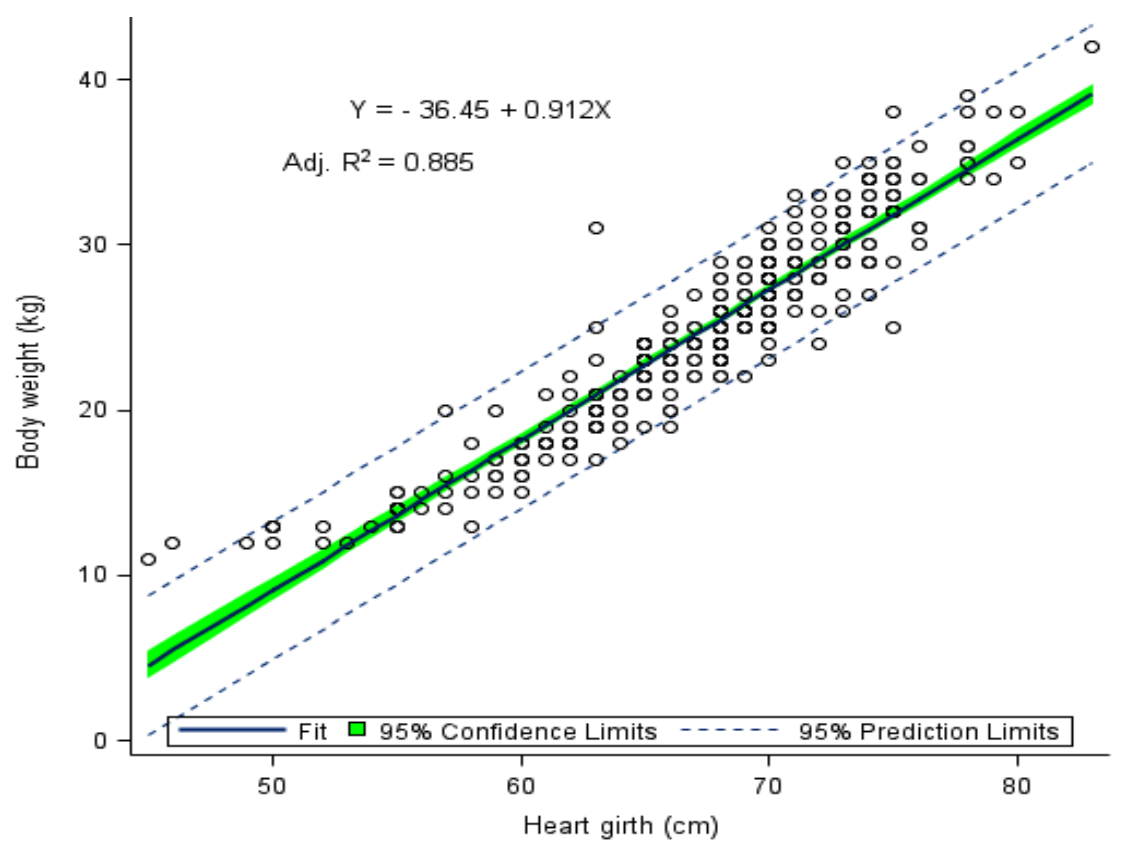

Fig. 1. Prediction pattern of body weight $(Y)$ of female Hararghe highland goat populations by fitting heart girth $(X)$ in the regression model.

indicating the proportion of total variability not explained by the discriminator variables between populations. This means that most $(59.7 \%)$ of the variability in the discriminator variables was due to differences between populations rather than variation within populations. The existence of phenotypic variation within and between populations is essential for the populations to successfully adapt to frequently changing climatic conditions and to successfully respond to artificial selection (Melesse et al., 2021). Wilk's
Lambda further tested the hypothesis that assumes that mean values of the agroecological zones are equal across goat populations and found to be highly significant, which confirms that differences observed among populations of the three zones were statistically different from zero. Similar to Wilk's Lambda value, the partial $\mathrm{R}^{2}$ static dropped down as significantly discriminating variables added chronologically, indicating that variability in each variable accounted for the population differences. 


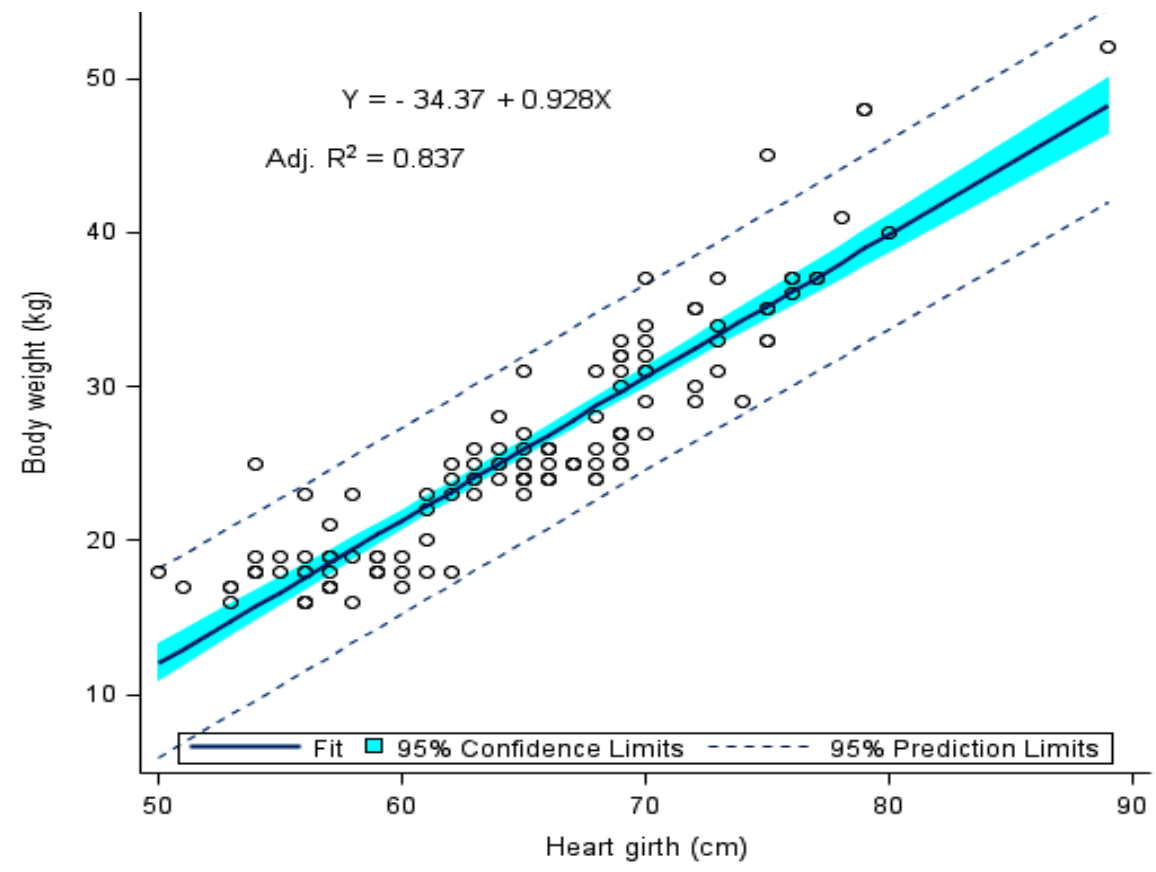

Fig. 2. Prediction of the body weight $(\mathrm{Y})$ of male Hararghe highland goat populations by fitting heart girth $(X)$ in the regression model.

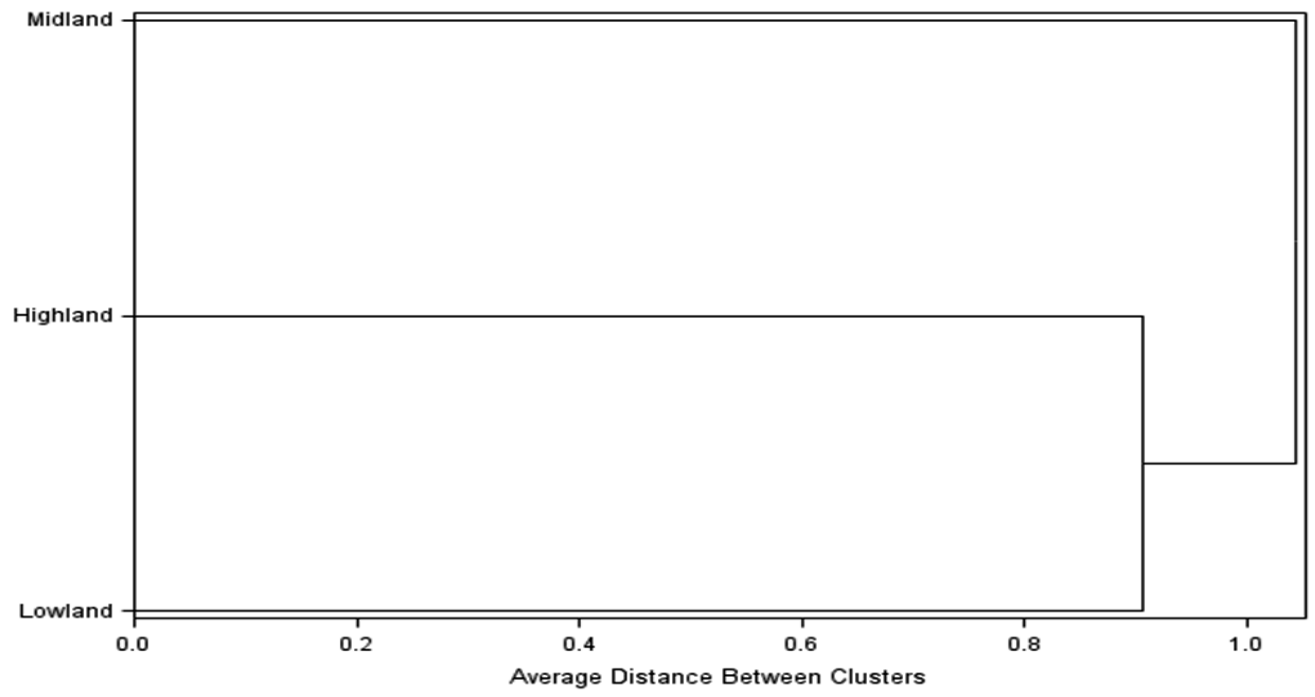

Fig. 3. Dendrogram based on the average linkage distance between the three goat populations using morphometric traits.

\section{Application of canonical discriminant analysis}

The Mahalanobis distances among the goat populations of the three agroecological zones based on morphometric traits are presented in Table 4. All the 11 traits were then subjected to canonical discriminant analysis using the CANDISC procedure that performed the uni- and multivariate analysis, the Mahalanobis distances, and eigenvalues of extracted canonical variables.

Canonical discriminant analysis identifies linear combinations of the morphometric traits that provide maximum separation between classes or groups. Determining the morphological distances will help understand the genetic 
Table 3. Summary of stepwise discriminant analysis for selection of traits.

\begin{tabular}{llccccccc}
\hline Step & $\begin{array}{c}\text { Variable } \\
\text { entered }\end{array}$ & $\begin{array}{c}\text { Partial } \\
\mathbf{R}^{2}\end{array}$ & $\begin{array}{c}\text { Wilk's } \\
\text { Lambda }\end{array}$ & $\begin{array}{c}\text { Pr } \\
\text { Lambda }\end{array}$ & $\begin{array}{c}\text { F value } \\
\text { Pr }>\text { F }\end{array}$ & $\begin{array}{c}\text { PSCC } \\
\text { ASCC }\end{array}$ \\
\hline 1 & Tail length & 0.183 & 0.817 & $<.0001$ & 50.08 & $<.0001$ & 0.092 & $<.0001$ \\
2 & Rump height & 0.199 & 0.654 & $<.0001$ & 55.34 & $<.0001$ & 0.177 & $<.0001$ \\
3 & Body weight & 0.140 & 0.563 & $<.0001$ & 36.31 & $<.0001$ & 0.236 & $<.0001$ \\
4 & Body length & 0.108 & 0.502 & $<.0001$ & 26.97 & $<.0001$ & 0.285 & $<.0001$ \\
5 & Ear length & 0.045 & 0.479 & $<.0001$ & 10.52 & $<.0001$ & 0.302 & $<.0001$ \\
6 & Chest width & 0.034 & 0.463 & $<.0001$ & 7.75 & 0.0005 & 0.312 & $<.0001$ \\
7 & Rump length & 0.027 & 0.450 & $<.0001$ & 6.21 & 0.0022 & 0.320 & $<.0001$ \\
8 & Heart girth & 0.039 & 0.433 & $<.0001$ & 8.84 & 0.0002 & 0.334 & $<.0001$ \\
9 & Head width & 0.026 & 0.421 & $<.0001$ & 5.95 & 0.0028 & 0.344 & $<.0001$ \\
10 & Chest depth & 0.026 & 0.410 & $<.0001$ & 5.93 & 0.0029 & 0.353 & $<.0001$ \\
11 & Head length & 0.016 & 0.403 & $<.0001$ & 3.67 & $<.0001$ & 0.359 & $<.0001$ \\
\hline
\end{tabular}

ASCC $=$ average squared canonical correlation.

Table 4. Mahalanobis distances among the goat populations of the three agroecological zones based on morphometric traits.

\begin{tabular}{lccc}
\hline Agroecology & Highland & Lowland & Midland \\
\hline Highland & 0 & 2.50 & 4.70 \\
Lowland & 2.50 & 0 & 3.32 \\
Midland & 4.70 & 3.32 & 0 \\
\hline
\end{tabular}

All Mahalanobis distances are significant at $p<0.0001$.

diversity of the indigenous animal populations and allow developing suitable breeding programs for the conservation of animal genetic resources (Melesse et al., 2021). The univariate analysis testing the hypothesis that class mean values are equal, which validates each morphometric variable in the sampled populations except for BW and RL, was a significant $(p<0.05)$ contributor to the total variation. The differences in goat population between agroecological zones were also tested by multivariate analysis and were significant $(p<0.0001)$. All pairwise squared Mahalanobis distances of the goat populations across agroecological zones were significant $(p<0.0001)$, which is in line with the findings of Melesse et al. (2021) and Tade et al. (2021). However, the smallest squared Mahalanobis distance (2.50) was observed between lowland and highland goat populations, indicating that they are homogenous and share similar genetic identities. This trend has been clearly demonstrated in the dendrogram displayed in Fig. 3. The smallest Mahalanobis distance value was found between lowland and highland goat populations because these populations are geographically located very close to each other. Meanwhile, the Mahalanobis distance was relatively moderate between lowland and midland (3.32) goat populations as well as between midland and highland (4.70) goat populations. In general, the Mahalanobis distances between goats of the three agroecological zones were small, indicating that the existence of homogeneity among the studied goat populations.

A summary of canonical correlations, eigenvalues, and likelihood ratios is presented in Table 5. The canonical discriminant analysis derives a linear combination of the traits that has the highest possible multiple correlations with the groups called the first canonical correlation. Accordingly, theanalysisidentified twostatistically significant $(p<0.0001)$ canonical variables $(\mathrm{CAN})$, with CAN1 and CAN2 accounting for 68.2 and $31.8 \%$ of the total variations, respectively, adding to $100 \%$ of that total variance, which indicates a complete representation of individuals of the goat populations with one scatter plot. The extracted canonical variables were found to be significantly different, which agrees with the observations of Traoré et al. (2008) for goat populations of Burkina Faso. On the contrary, Selolo et al. (2015) reported that the CAN1 was significant, while CAN2 remained insignificant for local South African goats. Rump height, and HDL dominated CAN1, while BL showed the largest influence on CAN2.

Fig. 4 shows a plot built with the two 
Table 5. Summary of canonical correlations, eigenvalues and likelihood ratios of the studied goat populations.

\begin{tabular}{lccccccr}
\hline & Canonical & \multicolumn{3}{c}{ Eigenvalues } & \multicolumn{2}{c}{ Likelihood } & Approximate \\
\cline { 3 - 7 } Function & correlation & Eigen value & Proportion & Cumulative & ratio & F-value & Pr > F \\
\hline CAN 1 & 0.667 & 0.804 & 0.682 & 0.682 & 0.403 & 22.82 & $<.0001$ \\
CAN 2 & 0.521 & 0.374 & 0.318 & 1.000 & 0.727 & 16.38 & $<.0001$ \\
\hline
\end{tabular}

CAN 1 = canonical variable 1 ; CAN 2 = canonical variable 2.

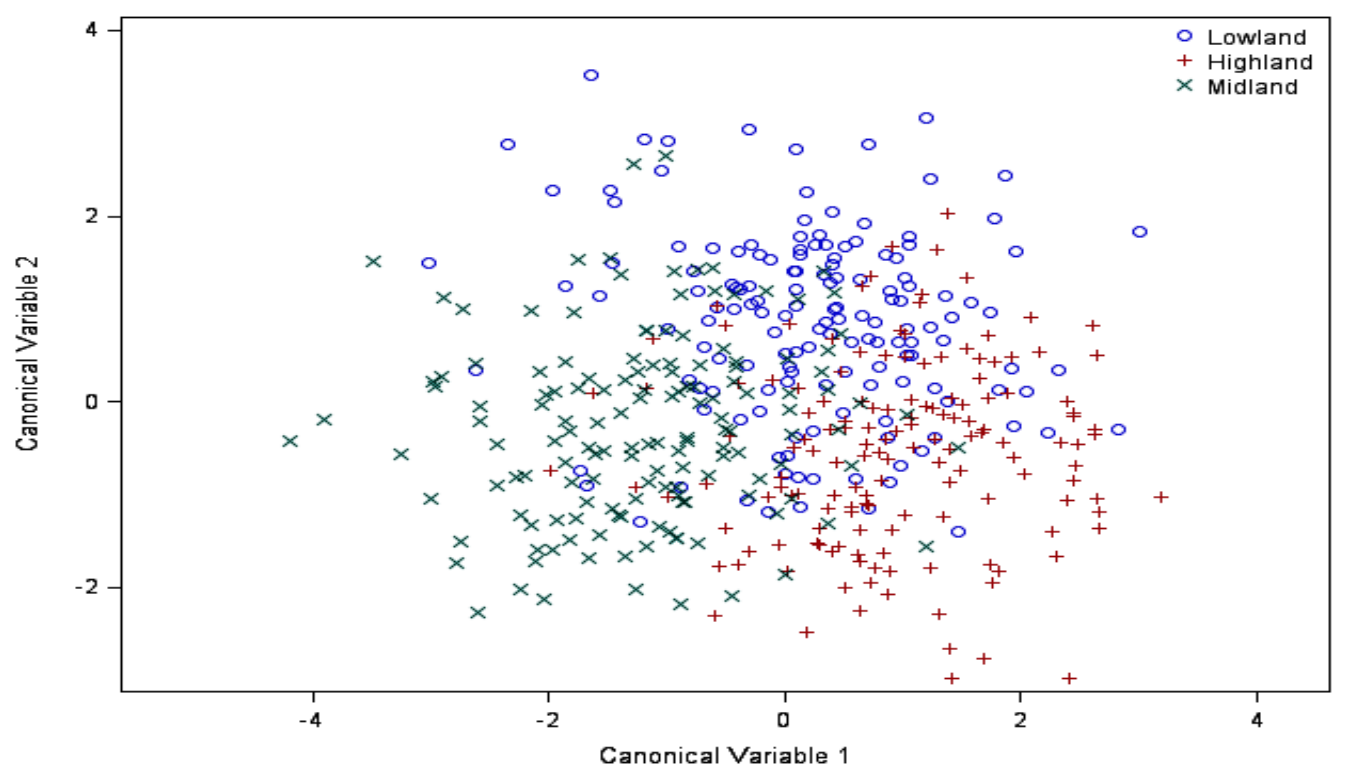

Fig. 4. Canonical representation of the goat populations of the three agroecological zones based on morphometric traits.

canonical variables, illustrating the relationships between goat populations belonging to different agroecological zones. The plot shows that CAN1 discriminates between midlands and highlands, while CAN2 discriminates between midlands and the other two agroecological zones. The values computed for CAN1 and CAN2 for each individual were plotted by agroecological zone and displayed in Fig. 4. Accordingly, the midland individuals were relatively homogeneous and clustered together on the left hand of the graph, while highland populations occupied the right side. Lowland goats showed an intermediate distribution but inclined towards highland individuals, indicating a visible overlapping among goat of the three agroecological zones, which in turns shows the existence of homogeneity among them.

\section{Application of discriminant analysis}

The discriminant analysis assumes that the individual group covariance matrices are equal (homogeneity within covariance matrices) and by default, it uses the linear discriminant function for classification. In the current discriminant analysis, equality of covariance matrices within groups was tested using Bartlett's test of homogeneity for all traits and was significant $\left(x^{2}=344.4 ; p<0.0001\right)$. Accordingly, the null hypothesis that assumes all covariance matrices within the goat populations are equal was rejected. Therefore, the withingroup covariance matrices were used to derive the quadratic discriminant function criterion for the classification of goat populations of the three agroecological zones.

As presented in Table 6, most of the highland and midland goat populations were classified into their source population (81.3, and $77.3 \%$, respectively), while the rest of them (10 and $14 \%$ ) were misclassified as lowland individuals. The discriminant analysis also allocated $71.3 \%$ lowland indigenous goats into their original agroecological zone. In agreement with the current observations, Selolo et al. (2015) found 
Table 6. Percent of individual goats classified into their respective agroecological zone and crossvalidation of classification based on morphometric traits (values in brackets are number of goats).

\begin{tabular}{lcccc}
\hline Agroecology & Highland & Lowland & Midland & Total \\
\hline Re-substitution & & & & \\
$\quad$ Highland & $81.3(122)$ & $10.0(15)$ & $8.67(13)$ & $150(100)$ \\
Lowland & $18.0(27)$ & $71.3(107)$ & $10.7(16)$ & $150(100)$ \\
Midland & $8.67(13)$ & $14.0(21)$ & $77.3(116)$ & $150(100)$ \\
Total & $36.0(162)$ & $31.8(143)$ & $32.2(145)$ & $450(100)$ \\
Error count estimate & 0.187 & 0.287 & 0.227 & 0.233 \\
Cross-validation & & & & \\
Highland & $70.7(106)$ & $16.0(24)$ & $13.3(20)$ & $150(100)$ \\
Lowland & $27.7(34)$ & $65.3(98)$ & $12.0(18)$ & $150(100)$ \\
Midland & $10.7(16)$ & $18.0(27)$ & $71.3(107)$ & $150(100)$ \\
Total & $34.7(156)$ & $33.1(149)$ & $32.2(145)$ & $450(100)$ \\
Error count estimate & 0.293 & 0.347 & 0.287 & 0.309 \\
\hline
\end{tabular}

that $60.3,58.1$ and $38.5 \%$ of the individual goats were classified into their original agroecological zone with several individuals being misclassified. Another study conducted by Dossa et al. (2007) indicated that more than $70 \%$ of individual goats were correctly allocated into their source populations. Similarly, the respective 79.3 and $82.7 \%$ of Sudan and Sudan-Sahel goat populations of Burkina Faso were classified into their source population (Traoré et al., 2008). Dekhili et al. (2013) reported that 73, 66.8 and $79.3 \%$ of Algeria goats were classified into North, Center, and South environments areas, respectively. All these reports suggest the importance of multivariate discriminant analysis to differentiate indigenous livestock populations reared in various production environments.

Based on the discriminant analysis, the overall average error count estimate was $23.3 \%$ for all observations and $76.7 \%$ of the overall sampled populations were correctly classified into their origin, indicating a lack of homogeneity of goat populations within agroecological zones for the variables included in the discriminant analysis. The relatively higher errors count estimate of classification for lowland goats (28.7\%) may indicate that they might have been extensively mixed with the other local goat populations. The misclassification observed in lowland goat populations suggests that they share a similar genetic basis with the other two goat populations. In addition, there is a good possibility of admixture among these goats because of the continuous migration of flocks that has existed for many generations and the existence of an active marketing system of goats in the region.

\section{CONCLUSIONS}

The current study shows that the live body weight of both male and female goats can be predicted using heart girth alone. The cluster analysis showed two separate clusters: cluster one included midland goat populations as one group, while cluster two included highland and lowland goats under one sub-cluster. Among the 16 variables, the stepwise discriminant analysis identified 11 as the most powerful variables to differentiate the goat populations. The Mahalanobis distances verified a similar trend in which lowland and highland goats were the closest, while midland and highland goats were the furthest. The canonical discriminant analysis further identified two canonical variables (CAN) of which CAN1 dominated by RH and HDL, and CAN2 dominated by BL, accounting for 68.2 and $31.8 \%$ of the total variation, respectively. This study revealed that the presence of variability in the observed morphometric traits among the studied goat populations of the three agroecological zones. Therefore, $\mathrm{HH}$ goat types in this zone may possess unique adaptive features that are useful in designing sustainable goat genetic improvement programs. Thus, designing a community-based breeding program is an important option for genetic improvement of Hararghe highland goat populations.

\section{ACKNOWLEDGEMENT}

This manuscript is a part of Ph.D. research work funded by the Oda Bultum University (Ethiopia). The authors are grateful for the 
received support and would also like to thank the farming community of the West Hararghe zone and the three districts, particularly for their cooperation during the collection of the morphological data from their goats.

\section{LITERATURE CITED}

Ahmed, S., K. Kefelegn, and E. Kefena. 2016. Morphological characterization of indigenous goats in Western Ethiopia: implication for community-based breeding programs. Anim. Genet. Resour. 58, 53-62. https://doi:10.1017/S2078633616000047.

Carneiro, H., H. Lovandini, S. R. Paira, F. Macedo, B. Mernies, and C. McManus. 2010. Morphological characterization of sheep breeds in Brazil, Uruguay and Colombia. Small Rumin. Res. 94, 58-64.

CSA (Central Statistics Agency). 2020. Agricultural sample survey, 2019/20 (2012 E.C). Volume II, Report on livestock and livestock characteristics (private peasant holdings). Statistical bulletin, 587. Addis Ababa, Ethiopia. https://www.statsethiopia. gov.et/our-survey-reports/

Dekhili, M., M. Bounechada, and I. Mannalah. 2013. Multivariate analyses of morphological traits in Algerian goats, Sétif, north-eastern Algeria. Anim. Genet. Resour. 52, 51-57. https://doi:10.1017/S2078633613000040.

Dossa, L.H., C. Wollny, and M. Gauly. 2007. Spatial variation in goat populations from Benin as revealed by multivariate analysis of morphological traits. Small Rumin. Res. 73, 150-159. https://doi.org/10.1016/j. smallrumres.2007.01.003

Ebert, R.A., and S. G. Solaiman. 2010. Animal Evaluation, In: Solaiman, S.G. (ed.), Goat Science and Production. (pp. 77-78). Blackwell Publishing Inc., Iowa, USA.

FAO. 2012. Phenotypic characterization of animal genetic resources. FAO Anim. Prod. Health Guidelines. No. 11. Rome, Italy.http://www. fao.org/docrep/015/i2686e/i2686e00.pdf

Gatew, H. 2014. On- farm phenotypic

characterization and performance evaluation of Bati, Borena, and Short Eared Somali goat population of Ethiopia. M.Sc. Thesis. Haramaya University, Haramaya. Ethiopia. https://cgspace.cgiar.org/bitstream/ handle/10568/53933/Theses_HulunimGatew. pdf?sequence

Gizaw, S. 2009. Goat Breeds of Ethiopia: A guide for Identification and Utilization. Alemu Yami, Kassahun Awgichew, T.A. Gipson and R.C. Merkel (eds). Technical Bulleting no.27. ESGPIP.
Haile, A., S. Gizaw, T. Getachew, J. P. Mueller, P. Amer, M. Rekik, and B. Rischkowsky. 2019. Community-based breeding programmes are a viable solution for Ethiopian small ruminant genetic improvement but require public and private investments. J. Anim. Breed Genet. 136, 319-328. https://doi:10.1111/jbg.12401.

IBC (Institute of Biodiversity Conservation). 2004. The State of Ethiopia's Farm animal Genetic Resources: Country Report. A Contribution to the First Report on the State of the World's Animal Genetic Resources. Addis Ababa, Ethiopia. http://www.fao.org/3/a1250e/ annexes/CountryReports/Ethiopia.pdf

Kurnianto, E., S. Sutopo, E. Purbowati, E. T. Setiatin, D. Samsudewa, and Permatasari. 2013. Multivariate analysis of morphological traits of local goats in Central Java, Indonesia. Iranian J. App. Anim. Sci. 3, 361-367.

Mekuriaw, G. 2016. Molecular characterization of Ethiopian indigenous goat populations: genetic diversity and structure, demographic dynamics and assessment of the kisspeptin gene polymorphism. Ph.D. Thesis in Applied Genetics, Addis Ababa University, Ethiopia. https://hdl.handle.net/10568/76315

Melesse, A., S. Banerjee, A. Lakew, F. Mersha, F. Hailemariam, and S. Tsegaye. 2013. Morphological characterization of indigenous sheep in Southern Regional State, Ethiopia. Anim. Genet. Resour. 52, 39-50. https://doi:10.1017/S2078633612000513

Melesse, A., G. Yemane, B. Tade, D. Dea, K. Kayamo, A. G. Genanew, Y. Mekasha, S. Betsha, and M. Taye. 2021. Morphological characterization of indigenous goat populations in Ethiopia using canonical discriminant analysis. Small Rumin. Res. In press 2021, 106591.

https://doi.org/10.1016/j.smallrumres.2021.106591

Musa, A. M., N. Z. Idam, and K. M. Elamin. 2012. Heart girth reflect live body weight in Sudanese Shogur Sheep under Field Conditions. World Vet. J. 2, 54-56.

SAS. 2012. SAS Release 9.4 Edition Statistical Analysis Systems Institute Inc., Cary NC, USA.

Selolo, T.C., M. L. Mashiloane, D. Norris, J. W. Ng'ambi, and D. Brown. 2015. Morphological differentiation of indigenous goats in different agro-ecological zones of Vhembe district, Limpopo Province, South Africa. Indian J. Anim. Res. 49, 527-531.https:// doi:10.5958/0976-0555.2015.00052.7.

Tade, B., A. Melesse, and S. Betsha. 2021. Application of multivariate analysis to differentiate the indigenous goat populations of South Gondar, Ethiopia. J. Agric. Envir. Sci. 6 (1):19-31. 
Traoré, A., H. H. Tamboura, A. Kaboré, L. I. Royo, I. Fernández, I. Álvarez, I. M. Sangaré, D. Bouchel, J. P. Poivey, D. Francois, L. Sawadogo, and F. Goyache. 2008. Multivariate analyses on morphological traits of goats in Burkina Faso. Archiv. Tierzucht. 51, 588-600. Tsegaye, D., B. Belay, and A. Haile. 2013. Morphological characterization of indigenous Hararghe highland goat breed in their native environment, West Hararghe, Ethiopia. American-Eurasian J. Scient. Res. 8, 72-79.

Yakubu, A., A. E. Salako, and I. G. Imumorin. 2011. Comparative multivariate analysis of biometric traits of West African Dwarf and Red Sokoto goats. Trop. Anim. Health and Prod. 43, 561-566. http://doi.org/10.1007/ s11250-010-9731-y
Yemane, G., A. Melesse, and M. Taye. 2020. Characterization of indigenous goat populations by applying morphometrical traits and structural indices. J. Vet. Res. Adva. 2, 22-31.

ZARDO (Zonal Animal Resource Development Office). 2017. West Hararghe Zone Animal Resource Development Office. Annual report 